\title{
Bewusstsein Wo wohnt der Geist?
}

T m heutigen Sprachgebrauch hat es sich eingebürgert, Geist 1 und Bewusstsein immer näher aneinander zu rücken. Der menschliche Geist scheint sich unter unserer Schädeldecke eingeschlichen zu haben, wo er wie sein englisches Gegenstück»the mind« hausen soll. Eine wichtige Frage unserer Zeit lautet, wie wir uns eigentlich unser mentales Vokabular der Selbstbeschreibung wieder verständlich machen können. Was heißt es, dass wir geistige oder gar rationale Lebewesen sind? Wir hängen die Begriffe »Geist« und »Bewusstsein« zusammen und sind nicht eigentlich genau für diese Frage die Geisteswissenschaften zuständig? Können sie sich zu einem Forschungsprojekt zusammenfinden, das den Geist aus verschiedenen Perspektiven untersucht? 